\title{
31. A Case of Partial Trisomy for the Long Arm of Chromosome 9
}

\author{
By Tetsuji Kadotani,*) Yoko Watanabe,*) Takako Kiyuna,*) \\ Toshimi KaWAmoto, ${ }^{*}$ and Ichiro TAKemurA**) \\ (Communicated by Sajiro MaKino, M. J. A., March 12, 1980)
}

Currently five cases associated with genuine partial trisomy for the long arm of chromosome 9, or partial trisomy $9 q$, are referred to in the literature (Turleau et al. 1975; Faed et al. 1976; Subrt et al. 1976 ; Chamla et al. 1977). We wish to describe in this article an additional case with an abnormal chromosome no. 1 carrying an inserted portion of the long arm $(9 q 12 \rightarrow 9 q 13)$ as partial trisomy $9 q$.

Case reports. The propositus was a thirteen-year-old boy, $32 \mathrm{Kg}$ in weight, with circumferences of $51 \mathrm{~cm}$ in head, $66 \mathrm{~cm}$ in breast, and $133 \mathrm{~cm}$ in length. He was born to a 22-year-old father and a 18-yearold mother as the first child. There was three spontaneous abortions in the first trimester, but no consanguinity in this couple. Both of her mother and father were phenotypically normal on the clinical examination.

Following clinical features were remarkable in the affected child: Imbecile, repeated convulsion, hard-dry and goose-fresh skin, dolichocephalia, flat occiput, upward slanted palpebral fissure, blepharophimosis, weak-sight, enlarged nasal bridge, irregular placement of teeth, low set ears, incomplete development of external genitalia, cryptorchism, and small penis (Fig. 1). Electrocardiogram was normal.

Cytological findings. Chromosome preparations were made from leucocyte cultures established from the propositus and his parents. For differential staining, the G-banding procedure was applied to airdried slides prepared from the above subjects. Chromosome counts were done on 60 well-delineated metaphases in each sample. Karyotypes were analysed on 24 cells in each based on conventional Giemsa and G-banding preparations.

The karyotype of the proband showed 46 chromosomes in which one no. 1 chromosome was outstanding by its enlarged long arm. The unusual element could not be assess until the maternal karyotype came under study. The examination of parents indicated that the

*) The Kadotani Medical Research Foundation. 1248, Saijohigashi, Saijo, Higashihiroshima, Hiroshima, Japan.

**) Kojika Educational and Medical Research Foundation. 4901, Awayacho, Miyoshi, Hiroshima, Japan. 
mother was the balanced carrier of direct insertion of a long arm segment of no. 9 into a long arm of no. 1 chromosome. The G-banding

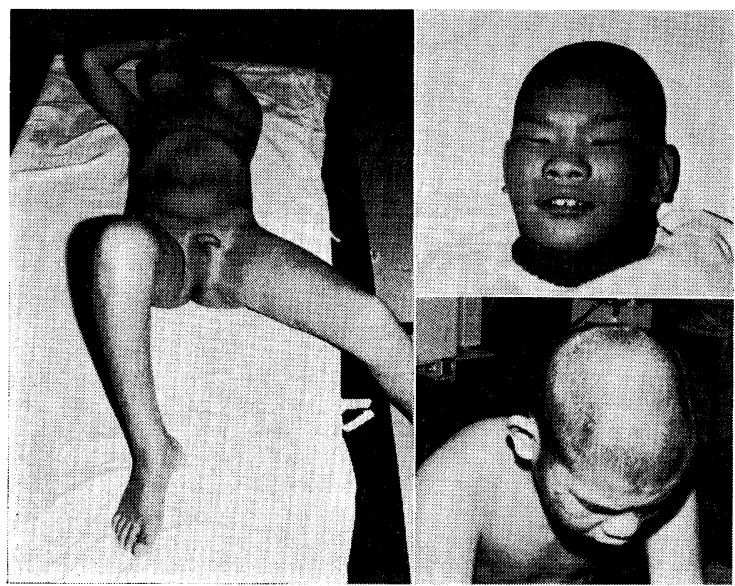

Fig. 1. Phenotypes of the propositus.

analysis revealed that the segment $q 12 q 13$ of chromosome 9 was missing and that this segment was inserted into the long arm of chromosome 1. Then, the formula of the mother was given as 46 , XX,ins $(1 ; 9)$ (q11; q12q13) (Fig. 3).

Based on the result from the maternal translocation, the aberration found in the propositus was interpreted as partial trisomy for

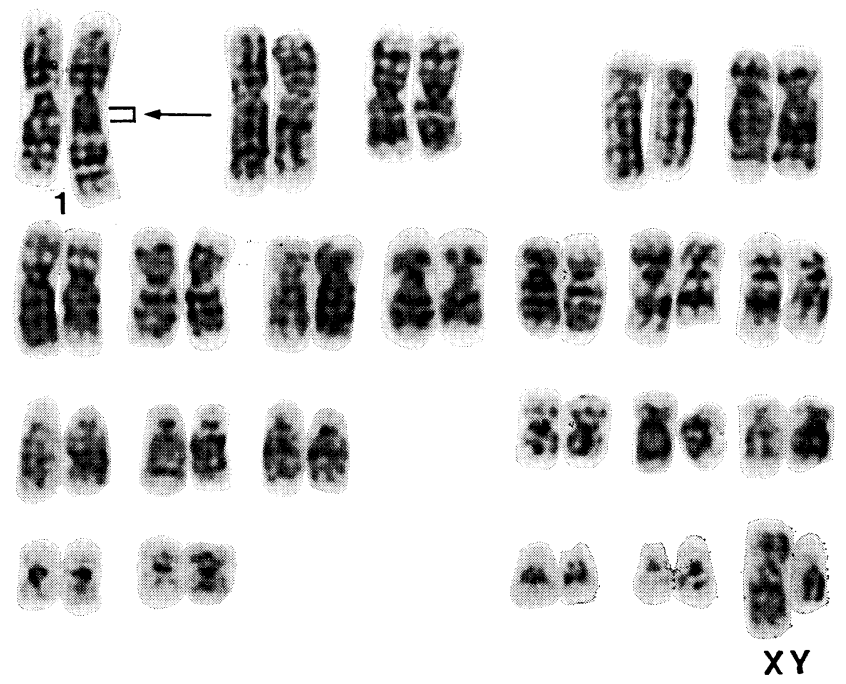

Fig. 2. G-banding karyotype of the propositus having an aberrant no. 1 chromosome which is a partial trisomy for long arm of no. 9 chromosome: 46,XY,der(1),ins(1; 9)(q11; q12q13)mat. 


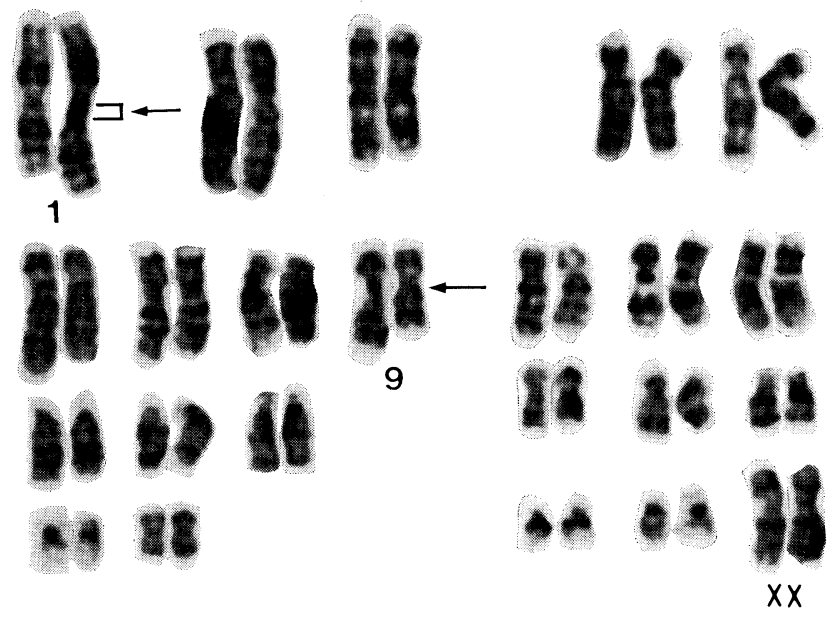

Fig. 3. G-banding karyotype of the mother having a direct insertion into a long arm of no. 1 chromosome from a long arm of no. 9: $46, \mathrm{XX}$,ins $(1 ; 9)(q 11 ; q 12 q 13)$.

the long arm of 9 . The formula was shown as 46,XY,der (1),ins (1;9) (q11; 12q13) mat (Fig. 2).

The father of the propositus was apparently normal in his karyotypes without showing any detectable chromosome change.

Remarks and conclusion. Recent banding techniques for the chromosome studies have served as very essential tools for the identification of the chromosome, as well as for the determination of translocation and of derivative chromosome.

The cases with partial trisomy for a long arm of no. 9 chromosome without association with trisomy $9 q$ are rarely referable to the recent literature.

Turleau et al. (1975) reported two unrelated patients with a partial trisomy for a long arm of chromosome 9. One patient had the duplication of the region q11q33, while the other showed trisomy for the segment q31qter. Faed et al. (1976) dealt with a case with partial trisomy for a long arm of chromosome 9 carrying a substantial portion of the long arm $(q 12 \rightarrow q 32)$ present in duplicate. Šubrt et al. (1976) reported a case with partial trisomy $9 q$ which showed trisomy for the segment q32qter. Chamla et al. (1977) described a case with partial trisomy $9 q$ involving the $9 q 11 \rightarrow 9 q 32$ region.

The major physical features of our case are shown in Table I in comparison with those reported in cases with partial trisomy 9q by the above-mentioned authors. It is evident that the clinical features are rather divergent depending on the difference of $9 q$ segments.

The partial trisomy $9 q$ observed in our case was shown to involve 


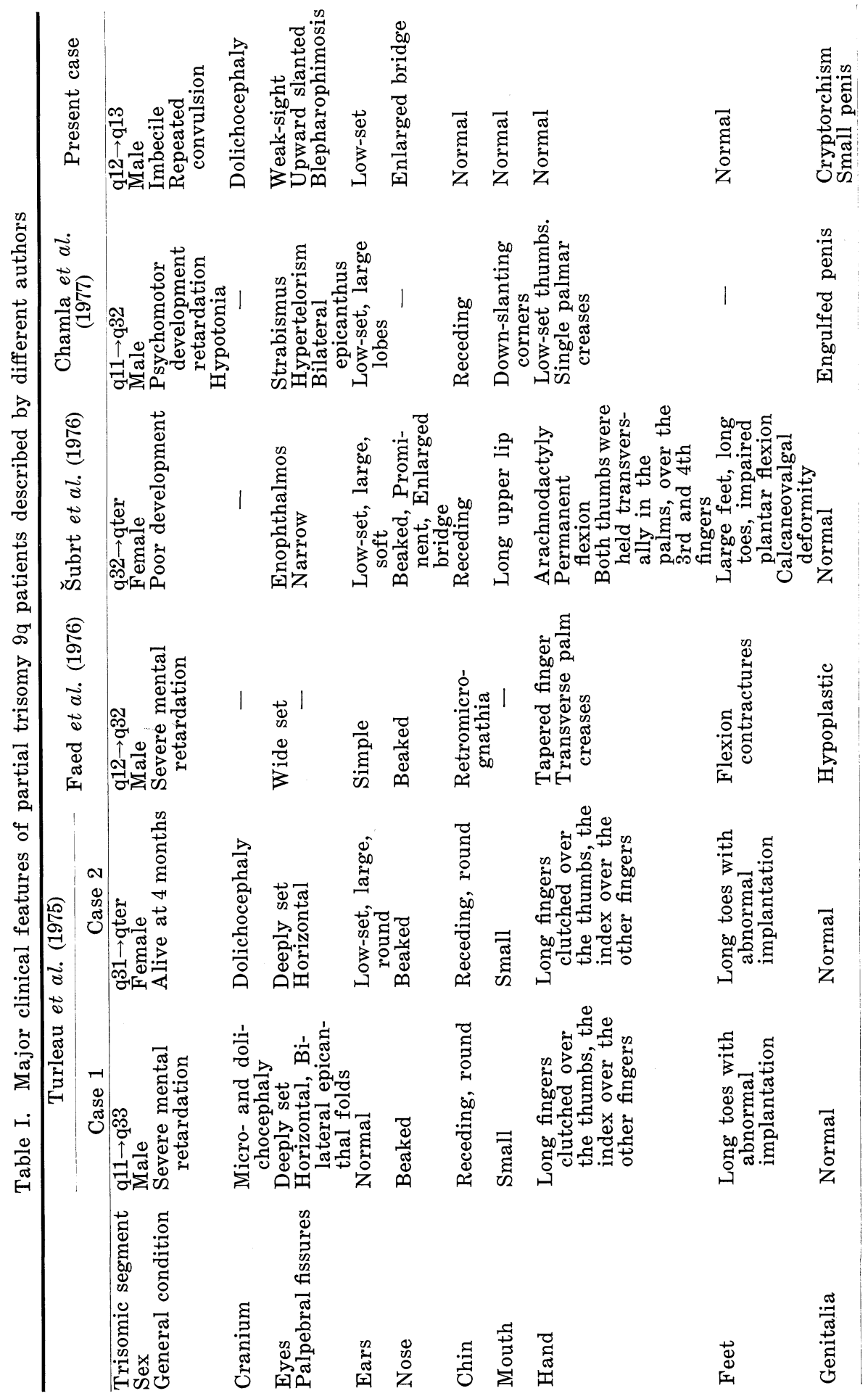


a very small segment of a long arm of a no. 9 which was represented by the band $q 12 \rightarrow q 13$ (Fig. 4). The mother of the proband is most probably a carrier of the direct insertion of a long arm of no. 9 (q12q13) into a long arm of no. 1 (1q11). She had in the past three spontaneous abortions. Very likely it might be from the unbalanced state of her gamates caused by deleted $9 q 12 \rightarrow q 13$.

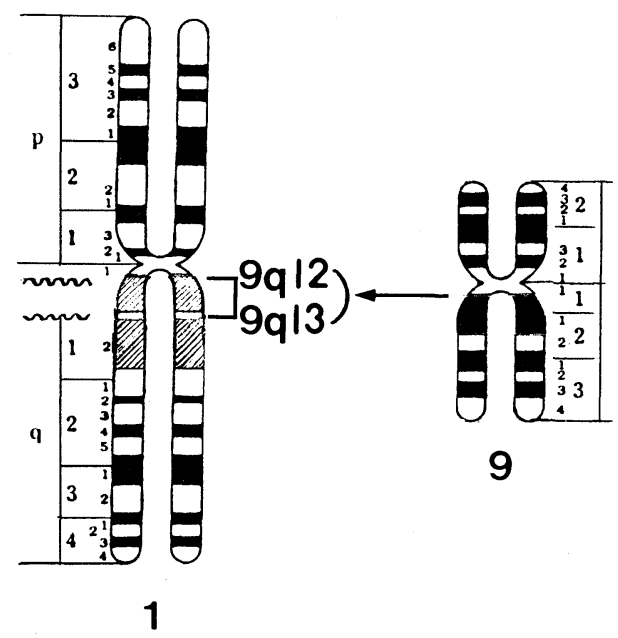

Fig. 4. Diagram showing direct insertion of a long arm segment of no. 9 (q12q13) into a long arm of no. 1.

The conclusion is then made that the propositus possesses the karyotype, 46,XY,der (1), ins $(1 ; 9)(q 11 ; q 12 q 13)$ mat, and his mother is a carrier of direct insertion, 46,XX,ins $(1 ; 9)(q 11 ; q 12 q 13)$.

Acknowledgements. We are much obliged to Emeritus Professor Sajiro Makino, M. J. A., the senior consultant of the Kadotani Medical Research Foundation, for improvement of this manuscript with invaluable advice, and to Mrs. Keiko Sasaki for her technical assistance. Financial aid from the Japan Academy is gratefully acknowledged here.

\section{References}

Chamla, Y., Bilbeissi, C., Micheau, M., and Battin, J. (1977) : Partial 9q trisomy associated with a 9, 21 translocation. Hum. Genet., 38, 245-248.

Faed, M., Robertson, J., Brown, S., Smail, P. J., and Muckhart, R. D. (1976) : Pure partial trisomy for long arm of chromosome 9. J. Med. Genet., 13, 239-242.

Šubrt, I., Janovský, M., and Jodl, J. (1976) : Partial trisomy 9q-chromosomal syndrome. Hum. Genet., 34, 151-154.

Turleau, C., de Grouchy, J., Chavin-Colin, F., Roubin, M., Brissaud, P. E., Repessé, G., Safar, A., and Borniche, P. (1975) : Partial trisomy 9q: A new syndrome. Humangenetik, 29, 233-241. 